\title{
Supermolecular structure and nucleation ability of polylactide- based composites with silica/lignin hybrid fillers
}

\author{
Aleksandra Grząbka-Zasadzińska ${ }^{1} \cdot$ Lukasz Klapiszewski $^{1} \cdot$ Karol Bula $^{2}$ • \\ Teofil Jesionowski $^{1} \cdot$ Sławomir Borysiak ${ }^{1}$
}

Received: 14 October 2015 / Accepted: 26 January 2016/Published online: 13 February 2016

(C) The Author(s) 2016. This article is published with open access at Springerlink.com

\begin{abstract}
In this paper, amorphous silica Syloid 244 and kraft lignin were mechanically coupled. Four hybrid materials containing silica and lignin in ratios 1:1, 2:1, 5:1 and 20:1 were prepared. As reference samples for hybrid fillers pristine silica and lignin were used. Particle size determination and microscopic observations were applied to determine dispersive and morphological properties of hybrid fillers. Fourier transform infrared spectroscopy confirmed the effective preparation of silica/lignin hybrid materials. The parameters of porous structure of examined hybrid filler were determined using the multipoint Brunauer-Emmett-Teller method and Barrett-Joyner-Halenda algorithm. Composite samples of polylactide (PLA) containing $2.5 \%(\mathrm{w} / \mathrm{w})$ of hybrid filler were extruded. Optical microscopy, wide-angle X-ray scattering and differential scanning calorimetry were applied to specify the supermolecular structure of functional PLA/hybrid composites and analyze the crystallization parameters as well as the phase transformation in PLA matrix. Silica/lignin hybrid material was found to be a filler capable of an effective crystal nucleation. The nucleating ability of silica/lignin hybrid filler in PLA matrix is related to porous properties of filler and its composition.
\end{abstract}

Sławomir Borysiak

slawomir.borysiak@put.poznan.pl

1 Faculty of Chemical Technology, Institute of Chemical Technology and Engineering, Poznan University of Technology, Berdychowo 4, 60965 Poznan, Poland

2 Faculty of Construction Engineering and Management, Institute of Materials Technology, Poznan University of Technology, Piotrowo 3, 60965 Poznan, Poland
Keywords Silica/lignin hybrid filler · Polylactide · Supermolecular structure $\cdot$ Biocomposites

\section{Introduction}

The production of polymers highly depends on refinery industry. The growth of environmental concern over the increase in the prices and availability of fossil resources has caused an intensification of research on polymers produced from renewable sources [1].

Polylactide (PLA) is a biodegradable engineering polymer with high mechanical strength and quite easy processability that makes it the most widely used bio-based thermoplastic polymer. It is used for packaging or medical applications (in form of films or fibers) also because of the fact that when exposed to high temperatures and high rates of humidity it relatively fast undergoes process of biodegradation [2]. However, PLA is a brittle material with low impact strength, representing one of its main limitations for the sustainable development of PLA [3]. The main concern regarding PLA is its low crystallization ability and degree as well as low heat resistance (deflection temperature $50-65^{\circ} \mathrm{C}$ ), significantly limiting its industrial applications, like automotive and electronics.

These problems can be solved by incorporating nanosized reinforcements within the polymer matrix. Various types of nanofillers have been considered as reinforcing agents to PLA matrix in order to enhance thermal resistance, fire resistance and mechanical properties [4]. Among them were fillers such as montmorillonite, sepiolite, halloysite, silica, carbon nanotubes, graphene, nanoceluloses, starch, silver nanoparticles, zinc oxide, as well as titanium dioxide [5-10]. The major challenge to develop PLA nanocomposites for advanced technological applications is 
understanding of the phenomena taking place at the interphase boundary polymer/filler and also supermolecular structure of polymer matrix in composite system. Although intensive research on polymer nanocomposite is being carried out, little work has been reported on PLA/filler nanocomposites. Previous works are mainly related to research on dispersion of nanoparticles in polymer matrix and mechanical properties of nanocomposites. Unfortunately, there is very limited number of works that involved determining the nucleation ability of filler in PLA matrix. Wang et al. [11] proved that the addition of the multiamide, heterogeneous, nucleating agent to PLA can effectively improve both nucleation ability and thermal resistance of the polymer. Also graphene exhibits the nucleating ability in the PLA matrix [12] causing the reduction in the nucleation induction period. It is reflected in the enhanced thermal stability of polymer matrix. In other work, cadmium phenylmalonate (PMA-Cd) was used as an inorganic filler for PLA [13]. The results showed that PMA-Cd accelerated the crystallization rate of PLA. Moreover, it increased the number of spherulites and decreased their size at the same time. Crystallization studies conducted with crystalline nanocellulose (CNC) showed that it plays an important role as a nucleating agent and contributes to an increase in the crystallization rate of PLA in the composite [5]. CNC modified with surfactant remarkably enhances the nucleation effect for PLA crystallization, too [14]. What is interesting, the results of DSC measurements presented in [15] demonstrate that cellulose nanowhiskers and poly(ethylene glycol) alone cannot be considered as nucleating agents for the PLA matrix.

In the last decade, much attention has been focused on polymer composites based on inorganic filler (including silica) [16-18] and lignin or cellulose [14, 19-21]. Inorganic fillers such as silica are attractive reinforcements that are able to significantly improve thermal, mechanical and also chemical properties of PLA-based biocomposites [4, 5]. Its valuable physicochemical properties along with high surface are the reasons for its widespread use [22, 23]. Silica exhibits also a great potential for surface functionalization in terms of physical and chemical features and therefore gains even more possible applications [24-30]. On the other hand, large amounts of lignin, as a by-product, are produced during kraft pulping process in paper production industry, causing it to be a low-cost, easily available filler. Moreover, it is a filler of natural origin, since lignin is a renewable, amorphous biopolymer derived from wood that is second only to cellulose in overall natural abundance [31]. Nonetheless, processing of lignin is very limited, because it degrades in temperature over $170{ }^{\circ} \mathrm{C}$ and its mechanical properties become impaired. Lignin is composed of phenylpropane repeat units and possesses aliphatic and aromatic hydroxyl groups. This functional group imparts a high polarity to the lignin macromolecule. Therefore, it exhibits high water sorption and low elongation rates that cause formation of air bubbles and hinder the flow through the injection nozzle [32].

Preparation of functional hybrid filler combining mechanical and thermal properties of inorganic silica with availability and low-cost organic lignin gains more interest these days [33, 34]. The resulting hybrid materials could be used as polymer fillers or biosorbents [33, 35, 36]. In terms of mechanical properties of composite materials, the concentration of hybrid filler in polymer matrix is crucial. However, the influence of functional hybrid filler on the supermolecular structure and morphology of the polymer matrix as well as phenomena at the interphase boundary matrix/filler cannot be omitted. Strong interphase surface transfers stresses appearing in the system and prevents the deterioration of its mechanical properties. Since lignocellulosic materials can heterogeneously nucleate crystallization along the interface with high density of nuclei, the resulting transcrystalline structures are believed to have a great influence on producing composites with good properties [37, 38].

In view of the above considerations, it is interesting to study whether the incorporation of $\mathrm{SiO}_{2} /$ lignin hybrid fillers can improve nucleation ability and affect the formation of supermolecular structure in PLA matrix. Although many efforts have been made to prepare PLA composites employing numerous fillers, there are no reports regarding PLA with $\mathrm{SiO}_{2} /$ lignin hybrid. Moreover, it is expected that the results will permit to better understand a relationship between the mechanical properties and morphology as well as nucleation activity of hybrid filler.

For that reason, the main purpose of this research was to evaluate the effect of physicochemical parameters of silica/ lignin hybrid material on their nucleation ability as well as on formation of supermolecular structure in PLA matrix.

\section{Materials and methods}

\section{Preparation of silica/lignin hybrid materials}

Commercial Syloid 244 silica (W.R. Grace \& Co., USA) and kraft lignin (Sigma-Aldrich, Germany) were combined using a mechanical method. Four $\mathrm{SiO}_{2}$ /lignin hybrid materials containing silica and lignin in ratios 1:1, 2:1, 5:1 and 20:1 were prepared. Later in this paper, $\mathrm{SiO}_{2} /$ lignin hybrid materials will be described as "hybrid," e.g., 20:1 hybrid stands for $\mathrm{SiO}_{2} /$ lignin in ratio 20:1. The initial powders of silica and lignin were ground and simultaneously mixed using a Pulverisette 6 Classic Line planetary ball mill (Fritsch, Germany). The mill was operated with a set inter$\mathrm{val}$, and the direction of rotation was changed every $15 \mathrm{~min}$ 
for $12 \mathrm{~h}$ with a speed ratio of 1:2. In order to prevent possible overheating of the material caused by the continuous grinding, the mill was automatically switched off for $5 \mathrm{~min}$ every $2 \mathrm{~h}$ and then turned on again. After the grinding process, produced hybrid materials were sifted using a sieve with a mesh diameter of $40 \mu \mathrm{m}$. The produced $\mathrm{SiO}_{2} /$ lignin hybrid materials were further characterized.

\section{Characterization of silica/lignin hybrid materials}

\section{Particle size distribution}

Zetasizer Nano ZS (0.6-6000 nm) (Malvern Instruments Ltd., UK) using the noninvasive backscattering technique was applied to determine particle size and the dispersive properties of the silica/lignin samples.

\section{Scanning electron microscopy (SEM)}

The morphology of samples was observed using a scanning electron microscopy (EVO40, Zeiss, Germany). Before testing, all the specimens were sputter-coated with gold for 5 s using a Balzers coater (PV205P, Balzers, Switzerland).

\section{Fourier transform infrared spectroscopy (FTIR)}

FTIR spectra were recorded on Vertex 70 spectrophotometer (Bruker, Germany) and used to confirm the presence of the expected functional groups. Materials were analyzed in form of tablets containing anhydrous $\mathrm{KBr}$ (ca. $0.1 \mathrm{~g}$ ) and $1 \mathrm{mg}$ of the tested material. Spectra were registered in wavenumber range of $4000-400 \mathrm{~cm}^{-1}$ (at a resolution of $0.5 \mathrm{~cm}^{-1}$ ).

\section{Porous structure properties}

The surface area was determined by the multipoint Brunauer-Emmett-Teller method, and the porous characteristics were defined by the Barrett-Joyner-Halenda algorithm. Surface area $\left(A_{\mathrm{BET}}\right)$ and total volume $\left(V_{\mathrm{p}}\right)$ of pores were determined using an ASAP 2020 instrument (Micromeritics Instrument Co., USA).

\section{Preparation of polylactide/silica-lignin hybrid composites}

Polylactide (Nature Works, LLC, Ingeo 2500HP, USA) and $2.5 \%(\mathrm{w} / \mathrm{w})$ of a hybrid filler were melt-blended in a corotating twin-screw extruder $(\phi=16 \mathrm{~mm}, L / D=40$, EHP 1614, ZAMAK, Poland) at and then cut with knife mill (25-16/TC-SL, TRIA, USA). Single-screw extruder ( $\phi=25 \mathrm{~mm}, L / D=30$, Metalchem, Poland) with slit die and chill-roll puller (pull speed $2.5 \mathrm{~m} / \mathrm{s}$ ) was used to produce films for further characterization. The first extrusion process was performed at a barrel temperature of $181-200{ }^{\circ} \mathrm{C}$ and a screw rotation speed of $145 \mathrm{rpm}$, whereas for the second extrusion the aforementioned parameters were subsequently $173-221^{\circ} \mathrm{C}$ and $79 \mathrm{rpm}$.

\section{Characterization of polylactide/hybrid composites}

Wide-angle X-ray scattering (WAXS)

The structure of composite materials was analyzed by means of wide-angle X-ray scattering (WAXS) using $\mathrm{CuK} \alpha$ radiation at $30 \mathrm{kV}$ and $25 \mathrm{~mA}$ anode excitation. The $\mathrm{X}$-ray diffraction patterns were recorded for the angle range from 5 to $30^{\circ}$ in the step of $0.04^{\circ} / 3 \mathrm{~s}$.

\section{Differential scanning calorimetry (DSC)}

Thermal properties of materials in form of films were evaluated using DSC (DSC 1, Mettler Toledo, USA) under argon atmosphere. For nonisothermal crystallization investigations, the samples were first heated from 40 to $210{ }^{\circ} \mathrm{C}$ at the rate $20{ }^{\circ} \mathrm{C} \mathrm{min}-1$ and kept at this temperature for $4 \mathrm{~min}$ to eliminate the previous thermal and/or mechanical history. Then, the samples were quenched to $40{ }^{\circ} \mathrm{C}$ at the rate $5{ }^{\circ} \mathrm{C} \mathrm{min}^{-1}$ and kept at $40{ }^{\circ} \mathrm{C}$ for $1 \mathrm{~min}$. This procedure was repeated two times, and the second tour was used in the calculations. Based on the determined values for the enthalpy of crystallization $(\mathrm{H})$, the extent of crystallization (crystal conversion), $\alpha$, was calculated (Eq. 1):

$\alpha=\frac{\int_{0}^{t}\left(\frac{\mathrm{d} H}{\mathrm{~d} t}\right) \times \mathrm{d} t}{\int_{0}^{\alpha}\left(\frac{\mathrm{d} H}{\mathrm{~d} t}\right) \times \mathrm{d} t}$

From the curves of $\alpha=f(t)$, the half-time of crystallization $\left(t_{0.5}\right)$ was determined as time when crystal conversion was $50 \%$. The crystallinity degree $\left(X_{\mathrm{c}}\right)$ of materials was evaluated according to Eq. 2.

$X_{\mathrm{c}}=\left(\frac{\Delta H_{\mathrm{m}}}{\Delta H_{\mathrm{m}}^{\circ} \times\left(1-\frac{\text { mass\% filler }}{100}\right)}\right) \times 100$

where $\Delta H_{\mathrm{m}}$ is the melting enthalpy (from second heating scan), $\Delta H_{\mathrm{m}}{ }^{\circ}$ is the melting enthalpy of a $100 \%$ crystalline polymer matrix (93.0 $\mathrm{J} \mathrm{g}^{-1}$ for PLA [2]) and mass\% filler is the filler mass percentage.

Furthermore, characteristic temperatures such as glass transition $\left(T_{\mathrm{g}}\right)$, melting $\left(T_{\mathrm{m}}\right)$ and crystallization $\left(T_{\mathrm{c}}\right)$ temperatures were defined.

\section{Polarized light microscopy (PLM)}

The isothermal crystallization of PLA in the presence of lignin, silica and hybrid filler was carried out using the hotstage optical (Linkam TP93, UK) and a polarizing optical 
microscope Nikon Eclipse (LV100POL, USA) equipped with a Panasonic CCD camera (GP-KR222, USA). The samples were first heated to $210{ }^{\circ} \mathrm{C}$ at the rate $40{ }^{\circ} \mathrm{C} \mathrm{min}{ }^{-1}$ and kept at this temperature for $5 \mathrm{~min}$ to eliminate the previous thermal and/or mechanical history. Then, the samples were cooled at $40^{\circ} \mathrm{C} \min ^{-1}$ to 136 or $138{ }^{\circ} \mathrm{C}$ at which isothermal crystallization of the PLA was allowed. Dry nitrogen was introduced to eliminate any possible degradation during measurement. The measurement lasted $16 \mathrm{~min}$ and photographs were taken every $10 \mathrm{~s}$. Analysis of the photographs was performed by means of MultiScan program, and in result, induction time (IT) and growth rate (GR) of the transcrystalline layer (TL) or spherulite were determined.

\section{Results and discussion}

\section{Physicochemical and dispersive-morphological properties of silica-lignin hybrid fillers}

The aim of the particle size distribution study was to determine dispersive and morphological properties of hybrid fillers. In Fig. 1, particle size distributions of hybrid fillers and its precursors are presented. Zetasizer Nano ZS results indicate the presence of particles in two ranges for each hybrid filler: 51-91 and 1480-4800 nm for 20:1 hybrid; 79-122 and 1720-5560 nm for 5:1 hybrid; 68-220 and 1990-4800 nm for 2:1 hybrid; and 106-295 and 1990-5560 nm for 1:1 hybrid. It has been found that the percentage of $\mathrm{SiO}_{2}$ in hybrid has an effect on decreasing particle sizes for a given fraction. On the contrary, the particle size of hybrid is influenced on lignin, whose particles are definitely bigger than those of $\mathrm{SiO}_{2}$.

Comparison of SEM microphotographs of silica (Fig. 2a), lignin (Fig. 2b) and hybrid fillers (Fig. 2c-f) confirms the findings of particle size distribution. Some primary particles can be observed, but the majority of them is combined and forms larger clusters of aggregates and agglomerates. However, the homogeneity of samples, resulting from ball milling method applied for grinding, is relatively good.

FTIR spectra of precursors (Fig. 3) as well as hybrid fillers (Fig. 4) were recorded in order to define and analyze its chemical structures. Bands observed for hybrid fillers and precursors are consistent with characteristic bands in range $1750-1000 \mathrm{~cm}^{-1}$ (see Table 1). It can be seen that for lignin numerous bands coming from aromatic skeleton, syringyl and guaiacyl units, $\mathrm{C}-\mathrm{H}, \mathrm{CH}_{3}$ and $\mathrm{CH}_{2}$ bendings were observed, while for silica only bands coming from $\mathrm{Si}-$ $\mathrm{O}-\mathrm{Si}, \mathrm{Si}-\mathrm{O}, \mathrm{Si}-\mathrm{OH}$ and moisture were recorded. As expected, vibrational frequencies wavenumber attributed to hybrid fillers come from both precursors. All of the bands characteristic for $\mathrm{SiO}_{2}$ and almost all of the bands characteristic for lignin were present on spectra of $\mathrm{SiO}_{2} /$ lignin hybrid fillers. Especially stretching vibrations of $\mathrm{O}-\mathrm{H}$ and $\mathrm{C}-\mathrm{H}$ bonds prove that obtaining $\mathrm{SiO}_{2} /$ lignin hybrid fillers was effective because the increase in the intensity was observed. What is also worthy of note, is the fact that depending on the $\mathrm{SiO}_{2}$ /lignin ratio in hybrid filler intensities of particular bands changed. The intensity of $1: 1$ hybrid filler bands coming from $\mathrm{SiO}_{2}$ precursor was similar to neat $\mathrm{SiO}_{2}$. With the increase in lignin in hybrid filler, the intensity of bands coming from lignin precursor tended to
Fig. 1 Particle size distribution for silica, lignin and hybrid fillers

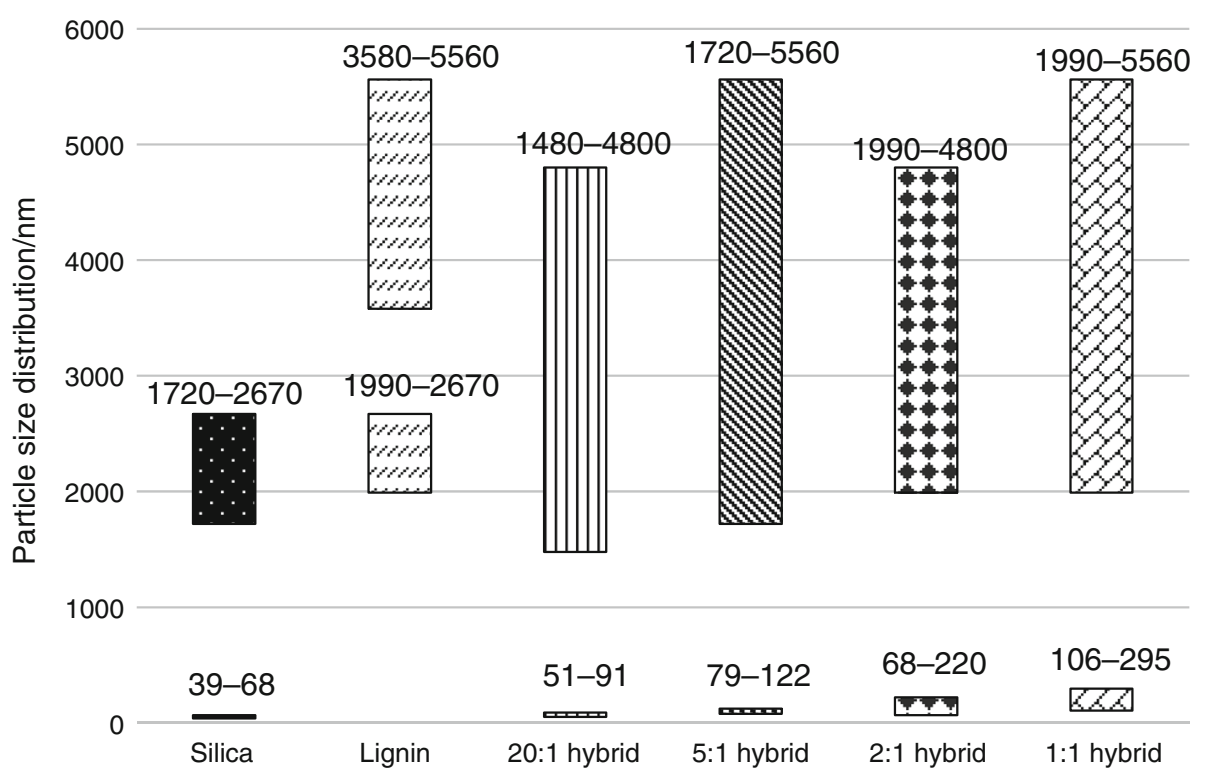


Fig. 2 SEM microphotographs of: a silica, b lignin, c 1:1 hybrid, d 2:1 hybrid, e 5:1 hybrid and f 20:1 hybrid. Scale bar $10 \mu \mathrm{m}$, except for lignin$100 \mu \mathrm{m}$
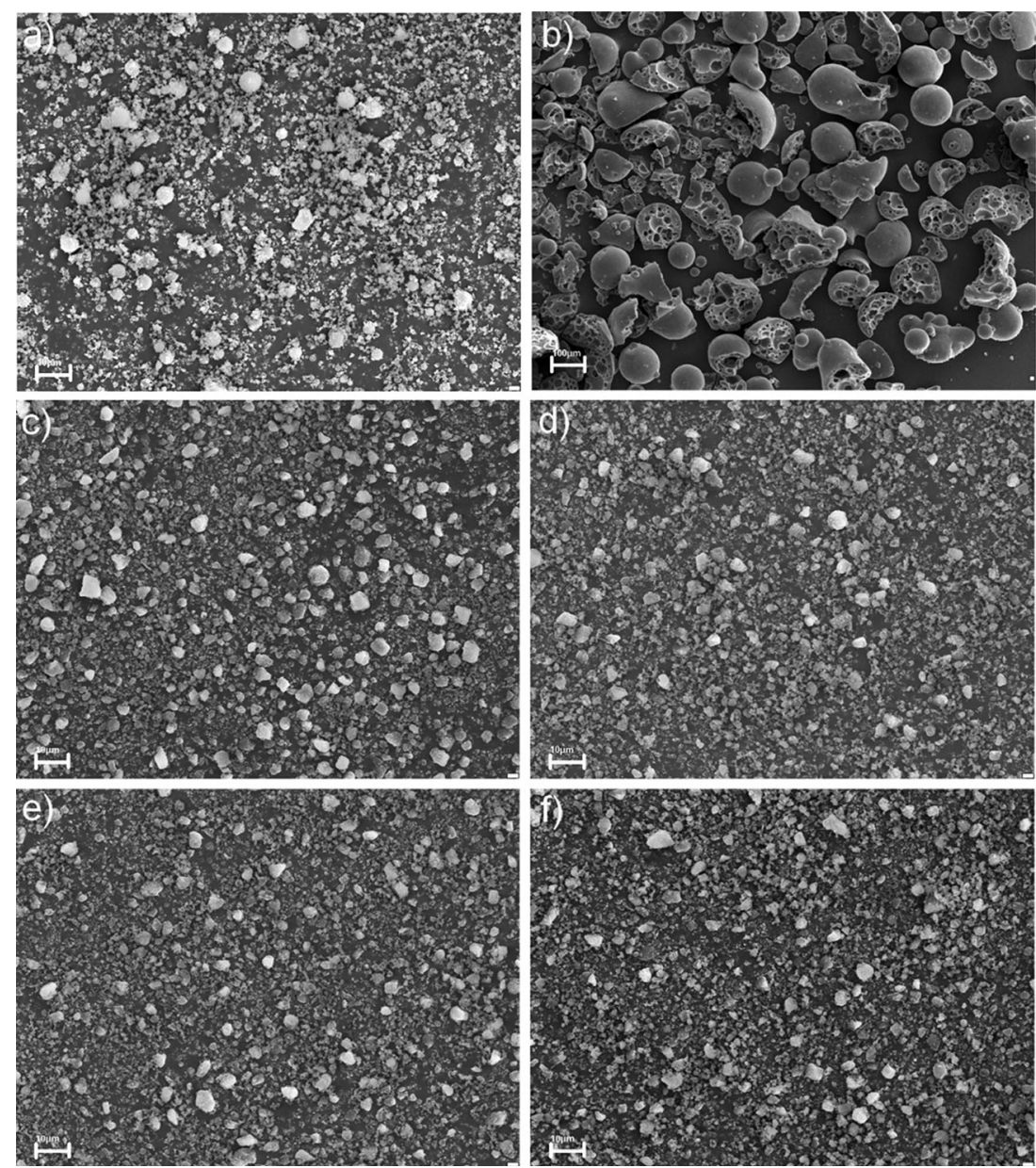

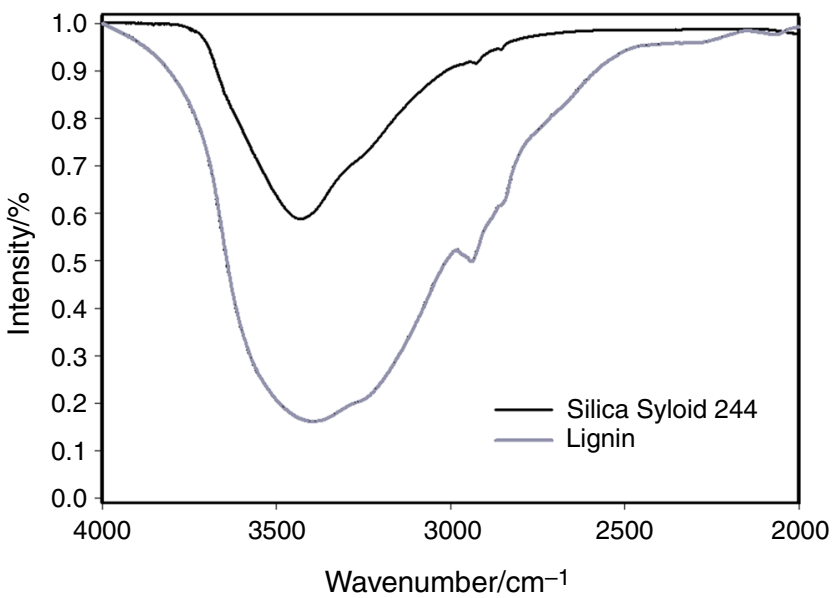

Fig. 3 FTIR spectra of silica and lignin

resemble bands noted for lignin. At the same time, bands typical for $\mathrm{SiO}_{2}$ became less intense. Nevertheless, all the spectra of hybrid fillers were characterized with the same bands, which confirms that their composition was different only in terms of $\mathrm{SiO}_{2} /$ lignin ratio.

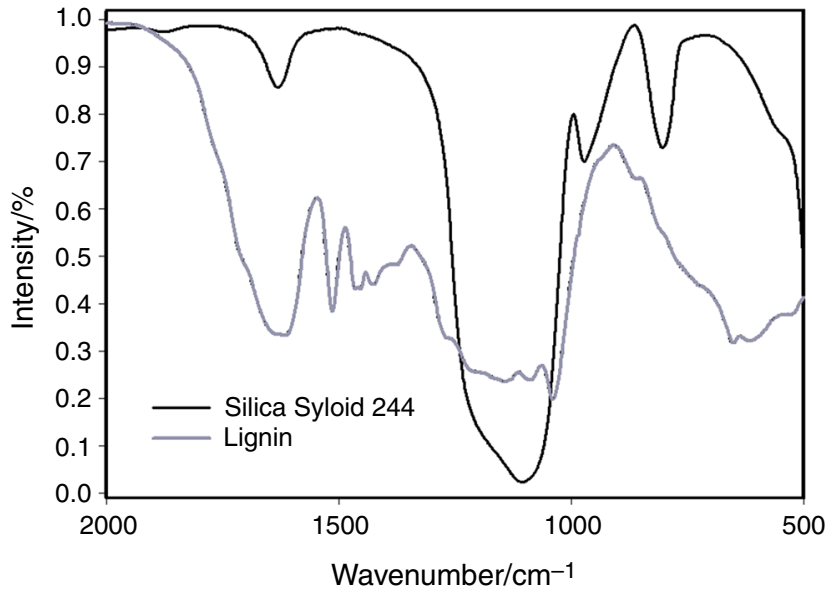

The BET surface area and the total pore volume were also determined (Fig. 5). The BET surface area value for silica equals $262 \mathrm{~m}^{2} / \mathrm{g}$, for lignin $1 \mathrm{~m}^{2} / \mathrm{g}$ and for hybrid materials $137-206 \mathrm{~m}^{2} / \mathrm{g}$. The total pore volume for silica was $0.12 \mathrm{~cm}^{3} / \mathrm{g}$, whereas for lignin $0.01 \mathrm{~cm}^{3} / \mathrm{g}$. Similarly 

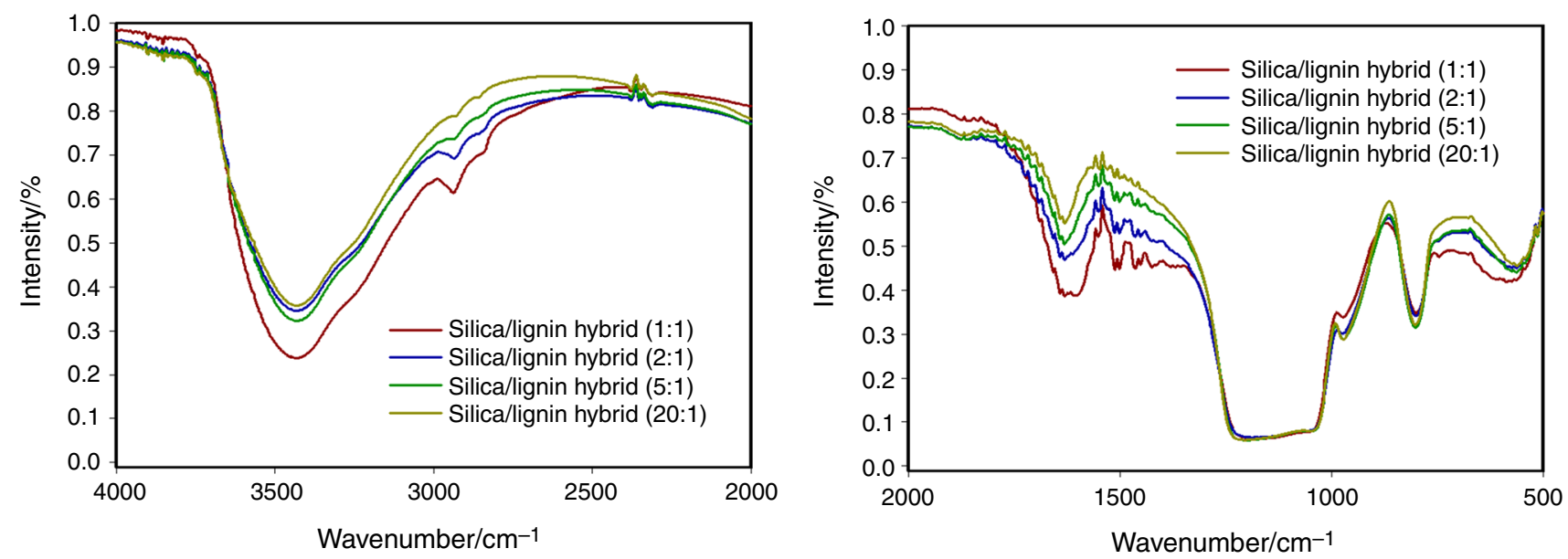

Fig. 4 FTIR spectra of hybrid fillers

Table 1 Vibrational frequencies wavenumber attributed to silica, lignin and hybrid fillers

\begin{tabular}{|c|c|c|c|}
\hline \multicolumn{3}{|c|}{ Wavenumber $/ \mathrm{cm}^{-1}$} & \multirow[t]{2}{*}{ Vibrational assignment } \\
\hline Silica & Lignin & Hybrid fillers & \\
\hline \multirow[t]{3}{*}{3420} & 3387 & 3430 & O-H stretching \\
\hline & $2980-2915$ & $2982-2923$ & $v_{\text {as }} \mathrm{C}-\mathrm{H}$ stretching \\
\hline & $2885-2840$ & $2883-2860$ & $v_{\mathrm{s}} \mathrm{C}-\mathrm{H}$ stretching \\
\hline \multirow[t]{11}{*}{1640} & & 1642 & $\mathrm{O}-\mathrm{H}$ (moisture) stretching \\
\hline & 1625 & 1642 & $\mathrm{C}=\mathrm{O}$ stretching \\
\hline & 1595 & & $\mathrm{C}-\mathrm{C}$ (aromatic skeleton) stretching \\
\hline & 1505 & 1512 & $\mathrm{C}-\mathrm{C}$ (aromatic skeleton) stretching \\
\hline & 1463 & 1469 & $\mathrm{C}-\mathrm{H}, \mathrm{CH}_{3}$ and $\mathrm{CH}_{2}$ bending \\
\hline & 1421 & 1423 & $\mathrm{C}-\mathrm{C}$ (aromatic skeleton) stretching \\
\hline & 1370 & & $\mathrm{O}-\mathrm{H}$ (phenolic $\mathrm{OH}$ ) bending \\
\hline & 1326 & 1328 & $\mathrm{C}-\mathrm{O}$ (syringyl unit) stretching \\
\hline & 1266 & & $\mathrm{C}-\mathrm{O}$ (guaiacyl unit) stretching \\
\hline & 1219 & 1213 & $\mathrm{C}-\mathrm{OH}$ (phenolic $\mathrm{OH}$ ) stretching \\
\hline & 1136 & & Aromatic $\mathrm{C}-\mathrm{H}$ (guaiacyl unit) stretching \\
\hline \multirow[t]{2}{*}{1096} & & 1096 & $\mathrm{Si}-\mathrm{O}-\mathrm{Si}$ symmetric stretching \\
\hline & 1040 & & $\mathrm{C}-\mathrm{OH}$ and $\mathrm{C}-\mathrm{O}-\mathrm{C}$ (aliphatic $\mathrm{OH}$ and ether) stretching \\
\hline \multirow[t]{2}{*}{960} & & 956 & $\mathrm{Si}-\mathrm{OH}$ stretching \\
\hline & 863 & & Aromatic $\mathrm{C}-\mathrm{H}$ (guaiacyl unit) bending \\
\hline \multirow[t]{2}{*}{805} & & 807 & $\mathrm{Si}-\mathrm{O}-\mathrm{Si}$ asymmetric stretching \\
\hline & 745 & 760 & Aromatic $\mathrm{C}-\mathrm{H}$ (guaiacyl unit) bending \\
\hline 470 & & 470 & $\mathrm{Si}-\mathrm{O}$ bending \\
\hline
\end{tabular}

to BET surface area, the value of this parameter tended to drop with the decrease in the amount of silica in hybrid and therefore reach values closer to those noted for lignin. In general, it can be seen that there is a relationship between particle size distribution and parameters of porous structure. The bigger was the fraction of small particles, the higher was the value of $V_{\mathrm{p}}$ and $\mathrm{A}_{\mathrm{BET}}$ parameter of tested material. Obtained results indicate that due to porous structure properties produced hybrid fillers are active by means of physical.

Analysis of the TG curves of hybrid filler $\left(\mathrm{SiO}_{2} /\right.$ lignin ratio 5:1) as well as its precursors is presented in our previous work [33]. However, it should be brought up that the hybrid filler was characterized by very good thermal properties. In comparison with initial sample mass, the mass loss for lignin and silica was, respectively, 65 and 
Fig. 5 Porous structure properties of silica, lignin and hybrid fillers

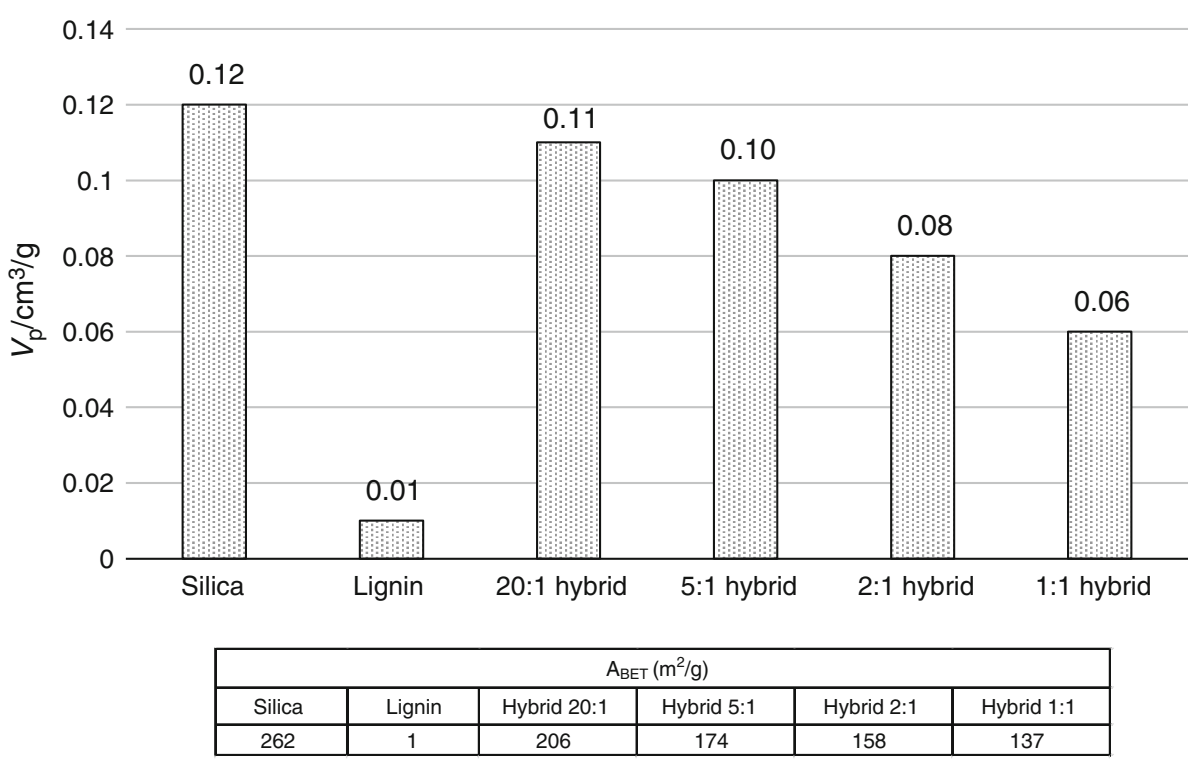

$7 \%$, whereas for hybrid filler the total mass loss over the entire temperature range was only $12 \%$. That is due to the fact that the amount of highly thermostable silica in hybrid filler was five times higher than lignin that undergoes decomposition during the measurement. Due to the partial condensation between native components, an increase in thermal stability of hybrid material in comparison with individual components is observed.

\section{WAXS diffraction analysis}

The objective of the WAXS study was to determine supermolecular structure of polymer matrix. Figure 6 presents WAXS diffraction patterns for PLA and PLA-based biocomposites. None of the tested film samples exhibited any peaks corresponding to crystalline structure. Produced composites were amorphous, and therefore, it can be stated that hybrid fillers do not have influence on formation of supermolecular structure of PLA.

\section{Polarized light microscopy (PLM)}

It is well known that the fillers may act as heterogeneous nucleating agents and nucleate crystallization along the interface with sufficiently high density of nuclei. The nucleation ability of certain fillers is extremely high so that subsequent crystal growth is normal to the surface of fillers until the growing front is impeded by the growth of spherulites nucleated in the bulk. The character of interfaces between the filler and the matrix in composite materials has been widely regarded as the most important factor determining their mechanical properties [38, 39].

Figure 7 shows selected photographs taken at $138{ }^{\circ} \mathrm{C}$ after 12 min. Photographs revealed that in PLA (Fig. 7a) and PLA/lignin (Fig. 7g) samples existed spherulites, whereas in composites with silica and hybrid filler (Fig. 7b-f) transcrystalline structures on matrix/filler interface were formed. In other words, the silica and $\mathrm{SiO}_{2} /$ lignin hybrid filler surface apparently plays a role as a kind
Fig. 6 WAXS diffraction patterns for PLA and PLAbased biocomposites

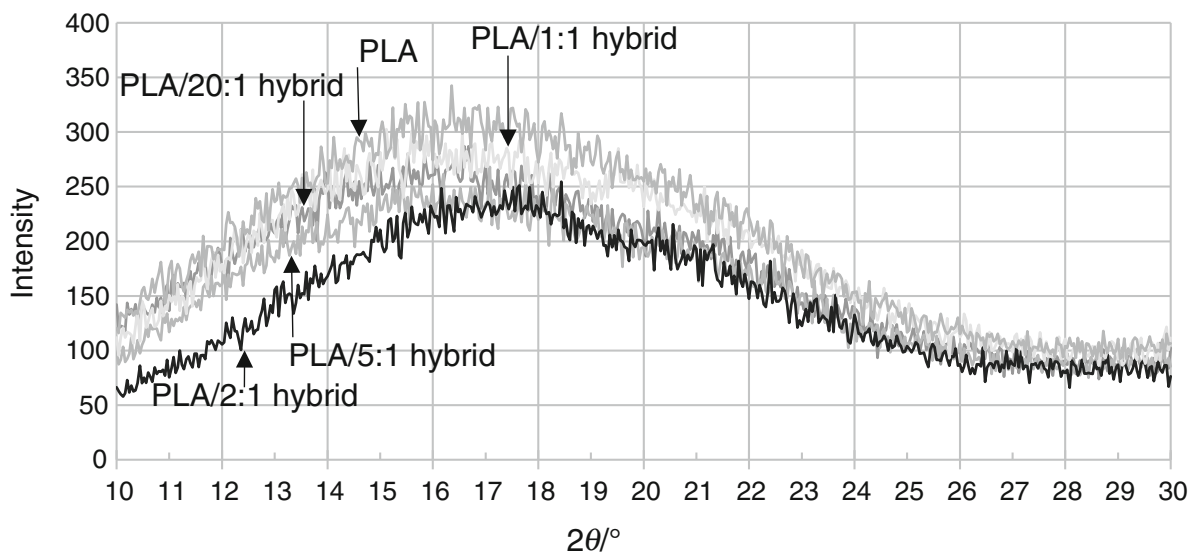


Fig. 7 PLM photographs taken at $138^{\circ} \mathrm{C}$ after 12 min: a PLA, b PLA/SiO $\mathrm{S}_{2}$, PLA/lignin, d PLA/1:1 hybrid, e PLA/2:1 hybrid, f PLA/5:1 hybrid and g PLA/20:1 hybrid. Scale bar $0.01 \mathrm{~mm}$
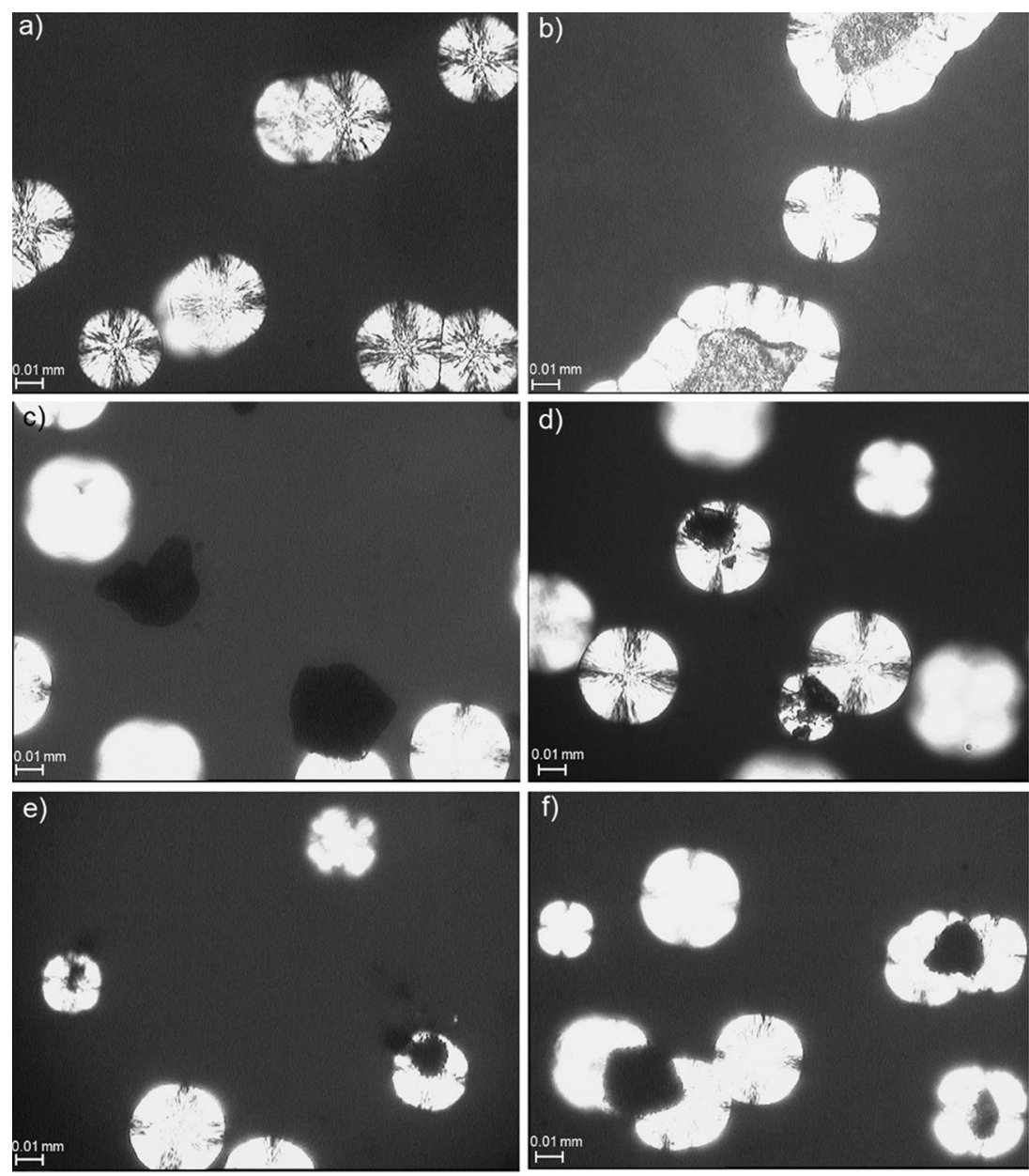

f)
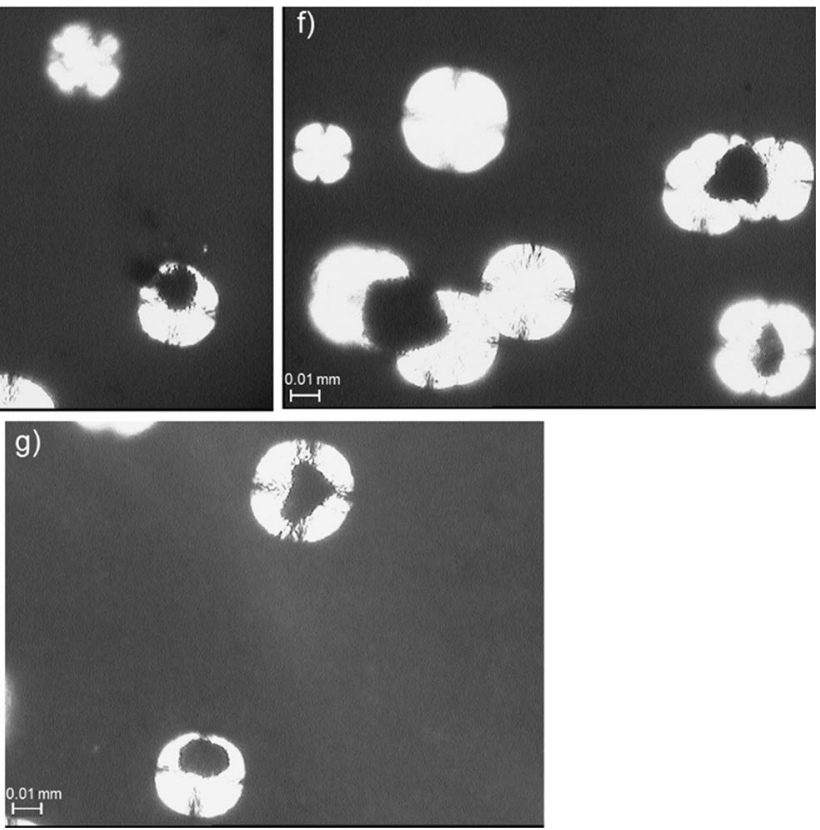

of nucleating agent for isothermal crystallization of PLA. It is worth emphasizing that the structures of the transcrystalline region of PLA in nanocomposite materials were not previously analyzed. Fujisawa et al. [40] observed the presence of spherulites only in neat PLA and not in PLA/ poly(ethylene glycol)/TEMPO-oxidized cellulose composites. This was ascribed to the dense network of composites prohibiting the three-dimensional growth of the PLA spherulites in the composites. It seems reasonable that the particle size along with porous properties (surface area and volume of pores) had an influence on formation of transcrystalline layer or spherulites. It can be seen that particles of nanometric sizes with high values of surface area and volume of pores, such as silica and hybrid fillers, contributed to formation of transcrystalline structures. In comparison with silica and hybrid fillers, lignin was characterized with significantly lower values of porous parameters and its particle sizes were definitely bigger (only micrometer size). Consequently, the lignin had no effect on the morphology of PLA which exhibits only spherulitic growth. Although the molecular mechanism of transcrystalline layer is still unclear, our results agree well with the literature [41] claiming that size of filler particles is a relevant variable in the crystallization process. 
Table 2 Crystallization kinetic parameters of PLA and PLA-based biocomposites

\begin{tabular}{|c|c|c|c|c|}
\hline & \multirow{2}{*}{$\begin{array}{l}\text { Induction time (IT)/s } \\
136^{\circ} \mathrm{C}\end{array}$} & \multicolumn{3}{|c|}{ Growth rate (GR) of the transcrystalline layer (or spherulite*)/ $\mu \mathrm{m} \min ^{-1}$} \\
\hline & & $138^{\circ} \mathrm{C}$ & $136^{\circ} \mathrm{C}$ & $138^{\circ} \mathrm{C}$ \\
\hline PLA & 120 & 130 & $7.90 *$ & $7.06 *$ \\
\hline PLA/silica & 130 & 140 & 3.38 & 3.10 \\
\hline PLA/lignin & 100 & 130 & $7.68 *$ & $7.18 *$ \\
\hline PLA/20:1 hybrid & 180 & 220 & 3.42 & 3.12 \\
\hline PLA/5:1 hybrid & 170 & 200 & 3.58 & 3.44 \\
\hline PLA/2:1 hybrid & 140 & 190 & 3.56 & 3.44 \\
\hline PLA/1:1 hybrid & 140 & 150 & 3.62 & 3.20 \\
\hline
\end{tabular}

* GR of the spherulite

Palza et al. also found that silica fillers with high specific area are characterized by larger heterogeneous nucleation than bigger filler.

PLM photographs were also used to define IT, GR of TL or spherulites (Table 2) and discuss the impact of composition of hybrid filler.

The highest GR was observed for PLA (7.06-7.90 $\mu \mathrm{m} \mathrm{min}^{-1}$ ) and PLA/lignin (7.18-7.68 $\mu \mathrm{m} \mathrm{min}^{-1}$ ) spherulites. GR of composites with hybrid filler was similar to $\mathrm{PLA} / \mathrm{SiO}_{2}$ and at the same time over $50 \%$ lower than the value of PLA and PLA/lignin. That indicates that porous structure properties of materials had influence on this parameter since lignin was undoubtedly characterized with the lowest value of $V_{\mathrm{p}}$ and $\mathrm{A}_{\mathrm{BET}}$ parameter. There was not much difference between GR values at 138 and $136{ }^{\circ} \mathrm{C}$; however, values of GR were slightly lower at $136{ }^{\circ} \mathrm{C}$.

Comparable situation took place for IT parameter. This should not be a subject of any doubts, because at higher temperatures the nucleation process lasts longer and accompanying growth rate is lower. The IT for $\mathrm{PLA} / \mathrm{SiO}_{2}$ sample was higher than for PLA/lignin, regardless of testing temperature. Furthermore, IT for $\mathrm{PLA} / \mathrm{SiO}_{2}$ composite was longer than for neat PLA, and at both temperatures, that difference was $10^{\circ} \mathrm{C}$. For hybrid filler composites, IT ranged from 150 to $220 \mathrm{~s}$, and in comparison with unmodified PLA, these values were higher. What is worth noting is that for both temperatures the IT parameter decreased as the amount of lignin in hybrid filler increased. This is clearly related to porosity and particle size of materials - the lower were the $A_{B E T}$ and $V_{p}$ values, the lower was also IT. And since lignin itself was characterized with the lowest $A_{\mathrm{BET}}$ and $V_{\mathrm{p}}$, the above-mentioned statement is understandable. For example, at $136{ }^{\circ} \mathrm{C}$ IT for the PLA/20:1 hybrid reached $180 \mathrm{~s}$ and for PLA/1:1 hybrid only $140 \mathrm{~s}$. Corresponding $\mathrm{A}_{\mathrm{BET}}$ and $V_{\mathrm{p}}$ values for these samples were $206 \mathrm{~m}^{2} / \mathrm{g}$ and $0.4 \mathrm{~cm}^{3} / \mathrm{g}$ for PLA/20:1 hybrid and $137 \mathrm{~m}^{2} / \mathrm{g}$ and $0.06 \mathrm{~cm}^{3} / \mathrm{g}$ for PLA/1:1 hybrid. Consequently, the highest IT was noted for PLA/20:1 hybrid sample. On the basis of our research, it can be concluded that smaller particle size and higher surface area of the hybrid filler (having more silica) did not necessarily provide an optimistic factor for enhancing the crystallization of PLA. Rather, the distribution of hybrid fillers in the polymer matrix was a more influential factor. Similar results were observed by Kose et al. [42], where smaller size of cellulose nanofibres does not necessarily make a better nucleating agent for PLA.

There are not many publications dealing with supermolecular structure of PLA/lignin and $\mathrm{PLA} / \mathrm{SiO}_{2}$ composites, and thus, the collected results can be compared only with polypropylene composites. For polypropylene/ $\mathrm{SiO}_{2}$ composites, Nitta et al. [43] proposed a mechanism of spherulite growth rate that is also applicable for PLA/hybrid materials. As it was already mentioned in PLM section, reduction in the average distance between adjacent $\mathrm{SiO}_{2}$ particles in composite causes lamellar clustering process.

Moreover, reduction in crystallization rates from spatial confinement of the precursor units into small volumes between adjacent particles leads to a retardation of the diffusive mobility of precursor or cluster units [43]. Noteworthy, the spherulite growth rate is drastically reduced when silica nanoparticles content increases. This result was explained by the restricted diffusive mobility of polymer chains due to the $\mathrm{SiO}_{2}$ nanoparticles. The reduced mobility of the polymer also decreasing the crystallization rate has been supported by other publication [44, 45]. The complexity of these systems is also confirmed by Kontou [46], who proved that the crystallinity of polymer nanocomposites can increase or decrease depending on the filler content. Reduction in nucleation ability (higher IT) may result from the spatial constraints on crystallizing PLA macromolecules introduced to the restricted space between particles. In consequence, it can be attributed to a reduction in mobility or molecular transportation of crystallizing units caused by the increase in silica nanospheres content.

Structures with the single chain space spontaneously built up from the melt and act as the crystallizing units. In 
result, the diffusive mobility of the units becomes restricted and the spherulite growth rate of polymer becomes impaired as the $\mathrm{SiO}_{2}$ content increases. According to the literature, cellulose induces the formation of TL [37, 47, 48]. The increase in cellulose content in wood (which consists of also lignin) is responsible for increase in nucleation abilities, which is related to epitaxy phenomena occurring on matrix/filler interface. It can be assumed that during the crystallization of PLA, lignin is not capable of inducing epitaxy phenomena. Moreover, it is likely that deterioration of nucleating abilities of lignin filler in PLA matrix is caused by the lack of geometric match in such composite.

However, further consideration of this problem is necessary, and in a future study, we intend to analyze the nucleation type (epitaxial, nonepitaxial) of hybrid fillers in polylactide matrix.

\section{Differential scanning analysis}

Figure 8 shows the DSC curves measured during the second cooling of the PLA and composite materials which were used to define characteristic temperatures, $X_{\mathrm{c}}$ and $t_{0.5}$ (Table 3).

For PLA, the shift of glass transition, cold crystallization, and melt temperatures to lower values is typical, since enhanced mobility of PLA chain mobility promotes crystallinity. Introduction of filler may increase or decrease $T_{\mathrm{g}}$, but it also may have no effect on it. The relative density of both the amorphous and crystalline regions influences the degree of crystallinity, and as a result, $T_{\mathrm{g}}$ can reach either higher or lower values [21].

For our composites, $T_{\mathrm{g}}$ was in range $62.8-63.5^{\circ} \mathrm{C}$, what is analogous to PLA sample $\left(63^{\circ} \mathrm{C}\right)$ and does not implicate any significant difference. Wen et al. [49] tested samples of PLA filled with different amounts of nanosilica (1, 3, 5, 7, $10 \%)$. Results obtained by that team were the same as those presented in this paper- $T_{\mathrm{g}}$ remained almost unchanged, indicating that the chain segment mobility of polymer matrix was not influenced by the introduction of $\mathrm{SiO}_{2}$ nanoparticles.

PLA/hybrid composites prepared in this study were characterized by $T_{\mathrm{c}}$ of about $3-5^{\circ} \mathrm{C}$ lower than the unmodified PLA. More considerable reduction in the $\mathrm{T}_{\mathrm{c}}$ was reported for PLA/nanosilica composites [49] and for PLA with cellulose nanocrystals (CNC) [14]. $\mathrm{T}_{\mathrm{c}}$ for PLA/ $3 \%$ nanosilica and for PLA/1 \% CNC composite shifted to lower temperature at ca. 25 and $30{ }^{\circ} \mathrm{C}$, respectively. In agreement with the literature, our results suggest that the incorporation of hybrid fillers enhances the ability of PLA to cold crystallization. The decrease in crystallization temperature was ascribed to the nucleating effect of the $\mathrm{SiO}_{2} /$ lignin hybrid filler, which accelerated the crystallization rate of PLA. However, PLA samples with 0-0.6\% of $\mathrm{N}, \mathrm{N}^{\prime}, \mathrm{N}^{\prime \prime}$-tricyclohexyl-1,3,5-benzenetricarboxylamide (TCM-328) nucleating agent were also tested in terms of
Fig. 8 Curves of PLA/hybrid samples

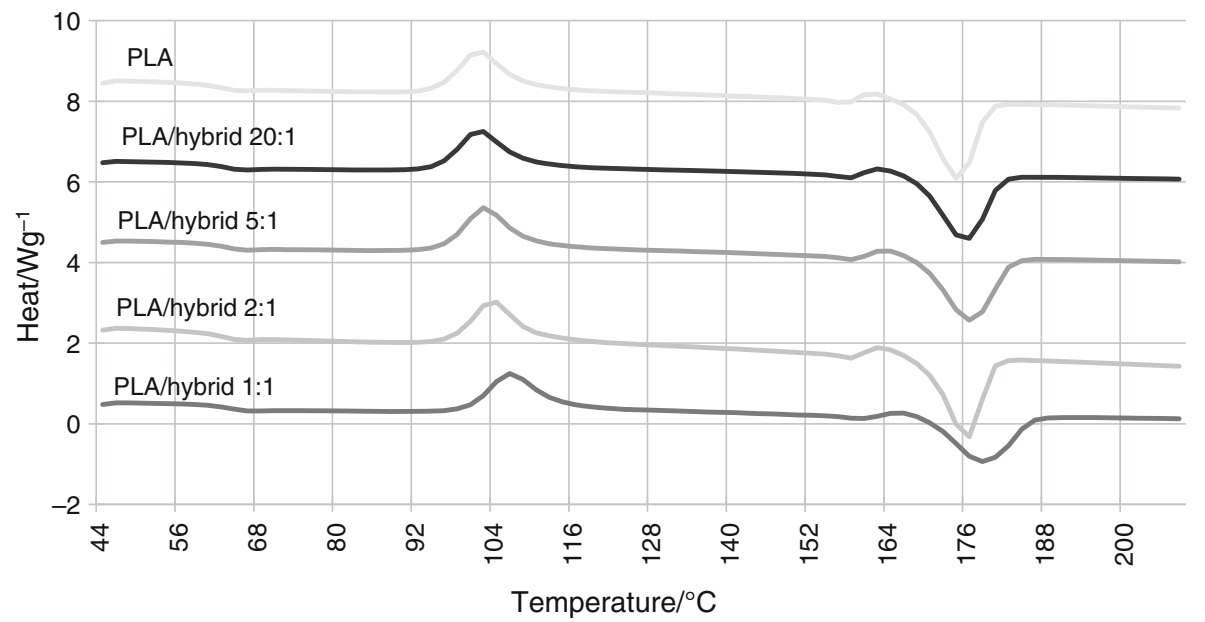

Table 3 Characteristic values of DSC measurements

\begin{tabular}{llllllll}
\hline & $T_{\mathrm{m}} /{ }^{\circ} \mathrm{C}$ & $T_{\mathrm{c}} /{ }^{\circ} \mathrm{C}$ & $T_{\mathrm{g}} /{ }^{\circ} \mathrm{C}$ & $\Delta H_{\mathrm{c}}$ & $\Delta H_{\mathrm{m}}$ & $X_{\mathrm{c}} / \%$ & 37 \\
\hline PLA & 177.5 & 106.4 & 63.2 & -26.01 & 34.69 & 45 \\
PLA/hybrid 20:1 & 175.3 & 103.3 & 62.8 & -25.33 & 42.62 & 47 \\
PLA/hybrid 5:1 & 175.3 & 102.1 & 63.5 & -25.49 & 43.48 & 48 \\
PLA/hybrid 2:1 & 174.9 & 101.4 & 63.3 & -26.73 & 41.25 & 46 \\
PLA/hybrid 1:1 & 173.9 & 101.4 & 62.9 & -24.10 & 42.24 & 38 \\
\hline
\end{tabular}


characteristic temperatures. It turned out that the addition of nucleating agent does not cause any major change in the $T_{\mathrm{g}}$ and $T_{\mathrm{c}}$ values [11]. On the contrary to above-mentioned publications, in PLA/lignin composites produced by Anwer et al. [19] an increase in lignin content caused the shift of $T_{\mathrm{c}}$ to higher temperature values. Also for PLA/graphene composites, that relationship was noticed [12].

In terms of $T_{\mathrm{m}}$, the discrepancy between reference sample $\left(177.5^{\circ} \mathrm{C}\right)$ and composites (173.9-175.3 $\left.{ }^{\circ} \mathrm{C}\right)$ was not very vast and consistent with other papers [21, 49].

Data regarding $X_{\mathrm{c}}$ reveal that addition of hybrid filler elevates this parameter from $37 \%$ for pure PLA up to 46-48 \% for PLA-based hybrid composites. Crystallization process is based on competition between the nucleation effect and polymer chain mobility for crystalline growth. Silica that is the main constituent of hybrid filler is well known for enhancing the $X_{\mathrm{c}}$ in PLA-based composites [49-51]. Particularly, nanosilica, due to its small size, has a large specific surface that is responsible for nucleating effect [52]. Also cellulose-based (nano)particles were found to be heterogeneous nucleation sites for PLA crystallization [5, 40]. It should be stressed that the increase in crystalline phase content in a composite is often responsible for enhancing mechanical properties of the material as it provides crosslinking sites which enhance the stiffness of the material in a similar way as the crosslinking density in thermoset resins [53].

Analysis of $t_{0.5}$ was important in terms of evaluation of the nucleation ability. The lower $t_{0.5}$ value was assumed as the higher crystallization rate. The nucleating properties of hybrid fillers were not affected by its composition. In comparison with unmodified PLA, $t_{0.5}$ for PLA/hybrid samples was definitely lower reaching 45 and 38-39 s, respectively. That confirms the fact that hybrid filler acted as nucleating agent for PLA.

Concluding, DSC measurements showed that the incorporation of hybrid fillers enhanced the ability of PLA to cold crystallization, which can be ascribed to the nucleating effect of the $\mathrm{SiO}_{2} /$ lignin hybrid fillers. Also $X_{\mathrm{c}}$ was affected by addition of the hybrid filler. The increase in $X_{\mathrm{c}}$ parameter was the result of the presence of silica in the hybrid filler which, due to its large surface area and high total volume of pores, acts as nucleating agent for PLA. For PLA/hybrid composites, in comparison with neat PLA $t_{0.5}$ was reduced; however, $\mathrm{SiO}_{2} /$ lignin ratio in PLA/ hybrid composites did not have any effect on $t_{0.5}$.

\section{Conclusions}

The subject of this study was to prepare and characterize polylactide composites filled with $\mathrm{SiO}_{2}$ /lignin hybrid material. DSC and PLM methods were used to investigate both phase transitions and transcrystalline effects during crystallization. Supramolecular structures of materials were investigated by WAXS technique. To the best of our knowledge, this is the first publication regarding PLA composites filled with $\mathrm{SiO}_{2}$ /lignin hybrid filler. The findings made from this study can be shortly summarized as follows:

- The presence of hybrid filler in PLA matrix has an influence on formation of transcrystalline layer and therefore influences the supermolecular structure of composites.

- Addition of hybrid filler does not influence the glass transition temperature. The introduction of $\mathrm{SiO}_{2}$ nanoparticles did not affect the chain segment mobility of polymer matrix.

- Composites with silica and hybrid filler form a transcrystalline structures on matrix/filler interface, whereas PLA and PLA/lignin composites form spherulites. The presence of $\mathrm{SiO}_{2}$ in hybrid filler restricts the formation of spherulites and thus is responsible for transcrystalline layer formation.

- $\mathrm{SiO}_{2}$ /lignin hybrid material is a filler capable of an effective crystal nucleation. This process, described by the growth rate and induction time parameter, is influenced by the amount of lignin in the filler and is closely connected with porous structure of filler.

- Half-time values decrease and the crystallinity rates increase with the increase in silica amount in the hybrid filler affirming its nucleating properties.

Acknowledgements This research was financed within the National Science Centre Poland funds according to decision no. DEC-2013/09/ B/ST8/00159.

Open Access This article is distributed under the terms of the Creative Commons Attribution 4.0 International License (http://crea tivecommons.org/licenses/by/4.0/), which permits unrestricted use, distribution, and reproduction in any medium, provided you give appropriate credit to the original author(s) and the source, provide a link to the Creative Commons license, and indicate if changes were made.

\section{References}

1. Pilla S. Engineering applications of bioplastics and biocomposites-an overview. Handbook of bioplastics and biocomposites engineering applications. New York: Wiley; 2011. p. 1-15.

2. Garlotta D. A literature review of poly(lactic acid). J Polym Environ. 2001;9(2):63-84. doi:10.1023/A:1020200822435.

3. Auras R, Harte B, Selke S. An overview of polylactides as packaging materials. Macromol Biosci. 2004;4(9):835-64. doi:10.1002/mabi.200400043.

4. Mróz P, Białas S, Mucha M, Kaczmarek H. Thermogravimetric and DSC testing of poly(lactic acid) nanocomposites. Thermochim Acta. 2013;573:186-92. doi:10.1016/j.tca.2013.09.012. 
5. Kamal MR, Khoshkava V. Effect of cellulose nanocrystals (CNC) on rheological and mechanical properties and crystallization behavior of PLA/CNC nanocomposites. Carbohydr Polym. 2015;123:105-14. doi:10.1016/j.carbpol.2015.01.012.

6. Kowalczyk M, Piorkowska E, Kulpinski P, Pracella M. Mechanical and thermal properties of PLA composites with cellulose nanofibers and standard size fibers. Compos A Appl Sci Manuf. 2011;42(10):1509-14. doi:10.1016/j.compositesa.2011.07.003.

7. Raquez J-M, Habibi Y, Murariu M, Dubois P. Polylactide (PLA)based nanocomposites. Prog Polym Sci. 2013;38(10-11):150442. doi:10.1016/j.progpolymsci.2013.05.014.

8. Robles E, Urruzola I, Labidi J, Serrano L. Surface-modified nanocellulose as reinforcement in poly(lactic acid) to conform new composites. Ind Crops Prod. 2015;71:44-53. doi:10.1016/j. indcrop.2015.03.075.

9. Awal A, Rana M, Sain M. Thermorheological and mechanical properties of cellulose reinforced PLA bio-composites. Mech Mater. 2015;80(Part A):87-95. doi:10.1016/j.mechmat.2014.09.009.

10. Świerz-Motysia B, Jeziórska R, Szadkowska A, Piotrowska M. Synthesis and properties of biodegradable polylactide and thermoplastic starch blends. Polimery/Polymers. 2011;56(4):271-80.

11. Wang L, Wang Y-n, Huang Z-g, Weng Y-x. Heat resistance, crystallization behavior, and mechanical properties of polylactide/nucleating agent composites. Mater Des. 2015;66(Part A):7-15. doi:10.1016/j.matdes.2014.10.011.

12. Valapa R, Hussain S, Iyer P, Pugazhenthi G, Katiyar V. Influence of graphene on thermal degradation and crystallization kinetics behaviour of poly(lactic acid). J Polym Res. 2015;22(9):1-14. doi:10.1007/s10965-015-0823-2.

13. Li C, Dou Q, Bai Z, Lu Q. Non-isothermal crystallization behaviors and spherulitic morphology of poly(lactic acid) nucleated by a novel nucleating agent. J Therm Anal Calorim. 2015;122(1):407-17. doi:10.1007/s10973-015-4677-y.

14. Fortunati E, Luzi F, Puglia D, Petrucci R, Kenny JM, Torre L. Processing of PLA nanocomposites with cellulose nanocrystals extracted from Posidonia oceanica waste: innovative reuse of coastal plant. Ind Crops Prod. 2015;67:439-47. doi:10.1016/j. indcrop.2015.01.075.

15. Wang X, Qu P, Zhang L. Thermal and structure properties of biobased cellulose nanowhiskers/poly (lactic acid) nanocomposites. Fibers Polym. 2014;15(2):302-6. doi:10.1007/s12221-0140302-0.

16. Wu J-H, Kuo MC, Chen C-W. Physical properties and crystallization behavior of poly(lactide)/poly(methyl methacrylate)/silica composites. J Appl Polym Sci. 2015;132(32). doi:10.1002/ app.42378.

17. Kim E, Kim S, Kim S. Preparation and characterization of monodisperse polystyrene-silica nanocomposites. Macromol Res. 2015;23(8):787-94. doi:10.1007/s13233-015-3097-y.

18. Opaprakasit P, Boonpa S, Jaikaew N, Petchsuk A, Tangboriboonrat P. Preparation of surface-modified silica particles from rice husk ash and its composites with degradable polylactic acid. Macromol Symp. 2015;354(1):48-54. doi:10.1002/masy.201400117.

19. Anwer MAS, Naguib HE, Celzard A, Fierro V. Comparison of the thermal, dynamic mechanical and morphological properties of PLA-Lignin \& PLA-Tannin particulate green composites. Compos B Eng. 2015;82:92-9. doi:10.1016/j.compositesb.2015.08.028.

20. Battegazzore D, Bocchini S, Alongi J, Frache A, Marino F. Cellulose extracted from rice husk as filler for poly(lactic acid): preparation and characterization. Cellulose. 2014;21(3):1813-21. doi:10.1007/s10570-014-0207-5.

21. Rahman MM, Afrin S, Haque P, Islam MM, Islam MS, Gafur MA. Preparation and characterization of jute cellulose crystalsreinforced poly(l-lactic acid) biocomposite for biomedical applications. Int J Chem Eng. 2014;2014:1-7. doi:10.1155/2014/ 842147.
22. Ojha S, Dang A, Hui CM, Mahoney C, Matyjaszewski K, Bockstaller MR. Strategies for the synthesis of thermoplastic polymer nanocomposite materials with high inorganic filling fraction. Langmuir. 2013;29(28):8989-96. doi:10.1021/la401522v.

23. Schlarb AK, Suwitaningsih DN, Kopnarski M, Niedner-Schatteburg G. Supermolecular morphology of polypropylene filled with nanosized silica. J Applied Polym Sci. 2014;131(1):n/a-n/a. doi:10.1002/app.39655.

24. Gorbachuk V, Ziatdinova R, Evtugyn V, Stoikov I. Stabilization of silica nanoparticles dispersions by surface modification with silicon derivative of thiacalix[4]arene. J Nanopart Res. 2015;17(3):1-13. doi:10.1007/s11051-015-2932-6.

25. Wang X, Wang P, Jiang Y, Su Q, Zheng J. Facile surface modification of silica nanoparticles with a combination of noncovalent and covalent methods for composites application. Compos Sci Technol. 2014;104:1-8. doi:10.1016/j.compscitech.2014.08.027.

26. Zhong B, Jia Z, Luo Y, Jia D. A method to improve the mechanical performance of styrene-butadiene rubber via vulcanization accelerator modified silica. Compos Sci Technol. 2015;117:46-53. doi:10.1016/j.compscitech.2015.05.012.

27. Bula K, Jesionowski T, Krysztafkiewicz A, Janik J. The effect of filler surface modification and processing conditions on distribution behaviour of silica nanofillers in polyesters. Colloid Polym Sci. 2007;285(11):1267-73. doi:10.1007/s00396-007-1687-8.

28. Jesionowski T, Zdarta J, Krajewska B. Enzyme immobilization by adsorption: a review. Adsorption. 2014;20(5-6):801-21. doi:10.1007/s10450-014-9623-y.

29. Jesionowski T, Bula K, Janiszewski J, Jurga J. The influence of filler modification on its aggregation and dispersion behaviour in silica/PBT composite. Compos Interfaces. 2003;10(2-3):225-42.

30. Bazhenov VV, Wysokowski M, Petrenko I, Stawski D, Sapozhnikov P, Born R, et al. Preparation of monolithic silica-chitin composite under extreme biomimetic conditions. Int $\mathrm{J}$ Biol Macromol. 2015;76:33-8. doi:10.1016/j.ijbiomac.2015.02.012.

31. Li J, He Y, Inoue Y. Thermal and mechanical properties of biodegradable blends of poly(L-lactic acid) and lignin. Polym Int. 2003;52(6):949-55. doi:10.1002/pi.1137.

32. Toriz G, Denes F, Young RA. Lignin-polypropylene composites. Part 1: composites from unmodified lignin and polypropylene. Polym Compos. 2002;23(5):806-13. doi:10.1002/pc.10478.

33. Bula K, Klapiszewski Ł, Jesionowski T. A novel functional silica/lignin hybrid material as a potential bio-based polypropylene filler. Polym Compos. 2015;36(5):913-22. doi:10.1002/pc.23011.

34. Jesionowski T, Klapiszewski Ł, Milczarek G. Kraft lignin and silica as precursors of advanced composite materials and electroactive blends. J Mater Sci. 2014;49(3):1376-85. doi:10.1007/ s10853-013-7822-7.

35. Klapiszewski Ł, Bartczak P, Wysokowski M, Jankowska M, Kabat K, Jesionowski T. Silica conjugated with kraft lignin and its use as a novel 'green' sorbent for hazardous metal ions removal. Chem Eng J. 2015;260:684-93. doi:10.1016/j.cej.2014. 09.054 .

36. Telysheva G, Dizhbite T, Evtuguin D, Mironova-Ulmane N, Lebedeva G, Andersone A, et al. Design of siliceous ligninsNovel organic/inorganic hybrid sorbent materials. Scripta Mater. 2009;60(8):687-90. doi:10.1016/j.scriptamat.2008.12.051.

37. Borysiak S. Influence of cellulose polymorphs on the polypropylene crystallization. J Therm Anal Calorim. 2013;113(1):281-9. doi:10.1007/s10973-013-3109-0.

38. Borysiak S. Fundamental studies on lignocellulose/polypropylene composites: effects of wood treatment on the transcrystalline morphology and mechanical properties. J Appl Polym Sci. 2013;127(2):1309-22. doi:10.1002/app.37651.

39. Bledzki AK, Reihmane S, Gassan J. Thermoplastics reinforced with wood fillers: a literature review. Polym Plast Technol Eng. 1998;37(4):451-68. doi:10.1080/03602559808001373. 
40. Fujisawa S, Zhang J, Saito T, Iwata T, Isogai A. Cellulose nanofibrils as templates for the design of poly(L-lactide)-nucleating surfaces. Polymer. 2014;55(13):2937-42. doi:10.1016/j. polymer.2014.04.019.

41. Palza H, Vera J, Wilhelm M, Zapata P. Spherulite growth rate in polypropylene/silica nanoparticle composites: effect of particle morphology and compatibilizer. Macromol Mater Eng. 2011;296(8):744-51. doi:10.1002/mame.201000405.

42. Kose R, Kondo T. Size effects of cellulose nanofibers for enhancing the crystallization of poly(lactic acid). J Appl Polym Sci. 2013;128(2):1200-5. doi:10.1002/app.38308.

43. Nitta K-h, Asuka K, Liu B, Terano M. The effect of the addition of silica particles on linear spherulite growth rate of isotactic polypropylene and its explanation by lamellar cluster model. Polymer. 2006;47(18):6457-63. doi:10.1016/j.polymer.2006.06.054.

44. Waddon AJ, Petrovic ZS. Spherulite crystallization in poly (ethylene oxide)-silica nanocomposites. Retardation of growth rates through reduced molecular mobility. Polym J. 2002;34 (12):876-81. doi:10.1295/polymj.34.876.

45. Xu J-T, Zhao Y-Q, Wang Q, Fan Z-Q. Isothermal crystallization of intercalated and exfoliated polyethylene/montmorillonite nanocomposites prepared by in situ polymerization. Polymer. 2005;46(25):11978-85. doi:10.1016/j.polymer.2005.10.004.

46. Kontou E, Niaounakis M. Thermo-mechanical properties of LLDPE/SiO 2 nanocomposites. Polymer. 2006;47(4):1267-80. doi:10.1016/j.polymer.2005.12.039.
47. Borysiak S. Influence of wood mercerization on the crystallization of polypropylene in wood/PP composites. J Therm Anal Calorim. 2012;109(2):595-603. doi:10.1007/s10973-012-2221-x.

48. Borysiak S, Doczekalska B. The influence of chemical modification of wood on its nucleation ability in polypropylene composites. Polimery/Polymers. 2009;54(11-12):820-7.

49. Wen X, Lin Y, Han C, Zhang K, Ran X, Li Y, et al. Thermomechanical and optical properties of biodegradable poly(L-lactide)/silica nanocomposites by melt compounding. J Appl Polym Sci. 2009;114(6):3379-88. doi:10.1002/app.30896.

50. Chrissafis K, Pavlidou E, Paraskevopoulos KM, Beslikas T, Nianias N, Bikiaris D. Enhancing mechanical and thermal properties of PLLA ligaments with fumed silica nanoparticles and montmorillonite. J Therm Anal Calorim. 2011;105(1):313-23. doi:10.1007/s10973-010-1168-z.

51. Santos FAd, Tavares MIB. Development and characterization of hybrid materials based on biodegradable PLA matrix, microcrystalline cellulose and organophilic silica. Polímeros. 2014;24:561-6. doi:10.1590/0104-1428.1653.

52. Huan G, Zhiguo Z, Huihui Y, Xiuqin Z, Rui W. Fabrication and properties of sc-PLA/SiO $\mathrm{S}_{2}$ composites. IOP Confe Ser Mater Sci Eng. 2014;62(1):012031.

53. Brazel CS, Rosen SL. Fundamental principles of polymeric materials. 3rd ed. New Jersey: Wiley; 2012. 